\title{
Sistemas Regionais de Inovação em Tecnologias Ambientais: A Experiência de North-Rhine Westphalia, Alemanha
}

Thierry Prates ${ }^{*}$

Maurício Serra ${ }^{* *}$

\section{Introdução}

Há um certo consenso na literatura econômica acerca da importância da dimensão local/regional no processo de desenvolvimento econômico, uma vez que as atividades econômicas buscam incessantemente locais de maior lucratividade, o que gera uma contínua reconstrução do local e uma crescente competição regional. $\mathrm{Na}$ realidade, as condições de desenvolvimento são efetivadas localmente, residindo o sucesso econômico destas localidades na sua capacidade de especialização em algo que tenha vantagens comparativas dinâmicas, que nada mais são do que o resultado do seu estoque de atributos e, principalmente, da sua capacidade de inovação. De fato, o processo inovativo é um aspecto primordial na vantagem competitiva local na medida em que ele está diretamente relacionado tanto à capacidade empresarial na promoção de Pesquisa e Desenvolvimento (P\&D) e na identificação de novos produtos ou processos que garantam o retorno financeiro das firmas, quanto à capacidade de aprendizagem local.

A inovação ocorre na dimensão local, através da interação direta entre os atores locais. Embora as novas tecnologias de comunicação tenham eliminado os obstáculos criados pela distância, a construção de vínculos de confiança e o aprendizado mais refinado ainda dependem fundamentalmente do contato direto e pessoal. De acordo com esta concepção, de matiz econômica neo-schumpteriana, a região é compreendida como sendo constituída por um conglomerado de instituições (empresas, instituições de ensino e pesquisa, etc.) que obtêm experiências positivas para se desenvolverem no decorrer do processo interativo, o que na literatura se convencionou denominar aprendizado por interação (learning region).

É dentro desta concepção que se situa a abordagem dos Sistemas Regionais de Inovação (SRI), fruto do arcabouço teórico dos Sistemas Nacionais de Inovação (SNI), que tem como principal característica o tratamento da inovação de maneira localizada e evolutiva, considerando os aspectos institucionais e sociais em que a inovação surge. Diferentemente da abordagem do SNI, que leva em conta os aspectos gerais de ciência e tecnologia dos países, a

\footnotetext{
* Doutor em Desenvolvimento Econômico pelo Programa de Pós-Graduação em Desenvolvimento Econômico da Universidade Federal do Paraná (PPGDE/UFPR). Professor do Departamento de Economia da Universidade Estadual de Ponta Grossa (UEPG). Endereço eletrônico: thierry_prates@hotmail.com.

** Doutor em Desenvolvimento Econômico pela London School of Economics (LSE). Professor do Departamento de Economia e do Programa de Pós-Graduação em Desenvolvimento Econômico da Universidade Federal do Paraná (PPGDE/UFPR). Endereço eletrônico: serra@,ufpr.br.
} 
análise da inovação através dos SRI deriva da relação entre as firmas, instituições de apoio e o entorno institucional local. Segundo Doloreux e Parto (2004), um SRI é caracterizado, por um lado, pela cooperação entre as firmas nas atividades de inovação e, por outro, pela atuação de universidades, institutos de pesquisa, organizações de treinamento e agências de transferência de tecnologia criando e difundindo conhecimento.

Um aspecto importante de ser sublinhado é que um SRI especializado em tecnologias ambientais, apesar de possuir características semelhantes aos demais sistemas, contempla algumas particularidades que têm influência somente nesse tipo de tecnologia, como a questão social e a regulação. A adoção dessas tecnologias é guiada por incentivos em parte distintos daqueles direcionados às tecnologias normais, utilizadas nos processos produtivos, cujo único objetivo é o aumento da produtividade.

Em função do fato do presente artigo agregar à abordagem de sistemas regionais de inovação a análise das tecnologias ambientais, cumpre tecer algumas considerações relativas às questões ambientais, que sempre foram tratadas marginalmente pelas teorias econômicas que discutem a inovação tecnológica e a produção industrial. Existem fortes implicações ambientais sobre a produção, o que significa que a estratégia das empresas contempla os aspectos ambientais relacionados à produção e tratar esses fatores de maneira exógena é um erro a ser corrigido pela teoria econômica.

A questão ambiental no âmbito da produção sempre foi alvo de discussões e controvérsias. Na realidade, a necessidade de se "limpar" o processo produtivo para que a vida na Terra não se tornasse insustentável era confrontada com o impacto nos custos gerados pela introdução de novas tecnologias, que não eram nocivas ao meio ambiente. A partir dos anos 90, as tecnologias limpas se consolidaram como uma solução necessária e viável, estando as razões para esta conclusão assentadas não somente num maior grau de consciência de que a degradação ambiental deve ser evitada a todo custo, como também no surgimento de importantes trabalhos acadêmicos que ressaltavam a viabilidade da implantação destas tecnologias e, ao mesmo tempo, o aumento da lucratividade advinda da sua adoção.

Existe uma crescente literatura a respeito das tecnologias ambientais como instrumento de redução de custos e competitividade, sendo o argumento de maior relevo a denominada hipótese de Porter, segundo a qual as empresas respondem à regulação através das inovações e que esse comportamento pode ser benéfico para a própria firma (Porter \& Van Der Linde, 1995a; 1995b; Porter, 1990). Os trabalhos relatam a importância da regulação ambiental no estímulo à inovação e na criação de mercados para produtos ambientais, assim 
como várias histórias de sucesso de empresas que implantaram processos limpos e reduziram custos. De acordo com Porter (1996), o conflito entre proteção ambiental e competitividade econômica é uma falsa dicotomia. As análises mencionadas demonstram que as empresas internacionais competitivas são as mais capazes de inovar, fundamentalmente em resposta a um estímulo regulatório.

Embora muitos problemas ligados à inovação ambiental estejam relacionados diretamente com a influência da regulação e da fiscalização e possam ser explicados parcialmente pela hipótese de Porter, a realidade mostra que não há apenas casos de sucesso ou uma saída simples para todas as firmas. Os exemplos de Porter e Van Der Linde (1995a) são sucessos na solução de problemas ambientais e redução nos custos. Contudo, os exemplos não representam firmas de todos os tamanhos e setores, não mostram as diferenças entre empresas que utilizam distintas quantidades de recursos naturais e nem mesmo aquelas que são atingidas com mais rigor pela regulação. Apesar dos autores admitirem que os seus exemplos não provam que as firmas podem sempre inovar para reduzir o impacto ambiental a um baixo custo, eles salientam que os exemplos mostram que existem oportunidades consideráveis para reduzir a poluição através de inovações que redesenham produtos, processos e métodos de operação (Porter \& Van Der Linde 1995b).

Além disso, a proximidade entre as firmas pode proporcionar um ambiente de confiança, troca de informações e ação conjunta. Em certos momentos, a cooperação entre os produtores pode ocorrer se o setor enfrenta uma crise, que pode ser derivada de uma maior pressão regulatória dos órgãos ambientais. Os países em que a regulação ambiental foi aplicada cedo e com rigor, foram aqueles que progrediram mais no processo de inovação, antecipando assim seus lucros e preenchendo um vazio existente na oferta, podendo então cobrar altos preços num mercado onde a competição não é muito acirrada e auferir lucros extraordinários (Barton, 1998).

As empresas que desenvolvem tecnologias ambientais não obedecem rigorosamente aos mesmos estímulos de mercado apresentados anteriormente. Um outro conjunto de fatores determina o processo desse tipo de inovação, entre eles o mais importante é o marco regulatório. De acordo com Skea (2000), as tecnologias ambientais dizem respeito a um grande número de termos que evoluíram para descrever a tecnologia associada à melhoria do desempenho ambiental. Processos que poupam energia, recursos naturais ou reutilizam materiais no processo de produção podem ser considerados exemplos clássicos de tecnologias ambientais. Todavia, o conhecimento acumulado nas empresas e instituições de pesquisa, 
gerando capacitação para criação de novos produtos e processos tecnológicos, também se inserem neste conjunto de conceitos que abrangem a tecnologia e, por conseguinte, a tecnologia ambiental.

As tecnologias ambientais podem, em geral, ser divididas entre End-of-Pipe - EOP (tecnologias de remediação) e Pollution Prevention - PP (tecnologias limpas) (OECD, 1985). As tecnologias de remediação estão relacionadas aos equipamentos que são anexados ao processo de produção para reduzir a poluição causada pela operação. A própria natureza da tecnologia, que tem de ser anexada à produção, eleva os custos. Esse tipo de tecnologia não é totalmente eficiente na medida em que simplesmente transfere, na maioria dos casos, a poluição de um meio para outro, sem evitá-la. Tecnologias limpas, por outro lado, dizem respeito às mudanças nos processos, que por sua própria natureza técnica geram menores níveis de poluição e rejeitos. Em geral, as tecnologias limpas são superiores às tecnologias EOP. Enquanto as tecnologias limpas previnem a poluição, as tecnologias EOP reagem à poluição existente (Skea, 2000).

A despeito do papel central da regulação, a inovação ambiental não pode ser considerada apenas uma resposta a este estímulo específico. Existem vários outros fatores que governam a inovação ambiental. Segundo Kemp, Smith e Becher (2000), os determinantes da inovação ambiental podem ser agrupados em três grupos: ^) os incentivos a inovar: dependem da intensidade da competição do mercado, das condições de custos e demanda (por exemplo, os custos de disposição de resíduos, preços de energia, demanda por produtos ambientalmente corretos, menores taxas de seguro para empresas ambientalmente corretas), e das condições de apropriabilidade (até que ponto uma inovação é capaz de capturar os benefícios econômicos de sua inovação); ii) a habilidade de assimilar e combinar conhecimento de diferentes fontes (dentro e fora da firma), que é necessária para produzir novos produtos e processos (conhecimento tecnológico e conhecimento do mercado); e iii) a capacidade de gerenciar o processo de inovação: forma especial de gestão. Gestão da atenção, gestão das idéias, gestão dos relacionamentos entre as partes, isto é, integração de funções, unidades e recursos.

O objetivo deste artigo é apresentar o Sistema Regional de Inovação (SRI) em Tecnologia Ambiental da região alemã de North-Rhine Westphalia de modo a compreender as suas particularidades no que tange a questão ambiental, a influência da regulação e dos mercados na decisão de investimento em processos limpos, e o estabelecimento das principais etapas que o sistema dessa região passou até alcançar a maturidade econômica e tecnológica. 
Para tanto, este artigo está estruturado em três seções. Na primeira seção, é apresentado o SRI ambiental alemão a partir de cinco dimensões analisadas: atores importantes; cooperação; governo; pesquisa e principais tecnologias; e resultados. A segunda seção mostra a evolução do SRI ambiental alemão, a qual está assentada em cinco parâmetros: pré-condições e surgimento do sistema; evolução da regulação e transformações na estrutura produtiva e tecnológica; desenvolvimento da infra-estrutura e canais de difusão tecnológica; caminhos para cooperação; e estágio atual e perspectivas para o futuro. Por fim, na última seção, algumas considerações finais são tecidas.

\section{O Sistema Regional de Inovação Ambiental de North-Rhine - Westphalia} (Alemanha)

North-Rhine Westphalia é um dos 16 estados da federação germânica e está situada no centro da Europa, tendo como fronteiras a Bélgica e a Holanda. É o estado mais populoso da Alemanha, com $22 \%$ do total da população e representa a área industrial mais significante da Alemanha, com $27 \%$ do produto industrial e $22 \%$ das exportações do país. O PIB da região em 1992 era equivalente aos PIBs da Coréia do Sul, Hong Kong e Tailândia somados. Os setores industriais líderes são: o químico, plásticos, engenharia mecânica e construção de aço, engenharia elétrica e eletrônica e alimentos. Um terço das 500 maiores companhias internacionais da Alemanha tem suas sedes em North-Rhine Westphalia, no entanto existem mais de 500.000 pequenas e médias empresas no território.

A região de North-Rhine Westphalia evoluiu economicamente a partir da produção de carvão e aço, no vale do Ruhr, a partir da metade século XIX. A indústria química surge após a segunda guerra, utilizando os produtos derivados das indústrias de mineração e aço. As tecnologias limpas emergem muito tempo depois, na década de 1970, para resolver os graves problemas causados pelas mesmas indústrias. Este talvez seja o exemplo mais marcante de sistema regional de inovação voltado para as tecnologias ambientais, no qual o problema ambiental foi transformado em mercado. Esse destaque é decorrente do pioneirismo nas iniciativas para controle da poluição nos anos 70. As principais características deste SRI no presente são apresentadas a seguir, de acordo com os parâmetros anteriormente citados. 


\section{a) Atores importantes}

Os principais atores que contribuíram para o sucesso local foram às firmas e governo. As firmas foram motivadas pela regulação e o apoio financeiro do governo na solução de problemas ambientais. Assim, implantaram-se mudanças radicais dentro da cadeia produtiva demandando soluções limpas, o que provocou um crescimento considerável no número de fornecedores de serviços ambientais na região, retirando a região mais atrasada (o vale do Ruhr) da estagnação econômica.

O governo teve uma função decisiva no desenvolvimento do sistema e participou ativamente, tanto do lado da regulação como do fomento à inovação, através de investimentos em infra-estrutura tecnológica e fomento a projetos. Algumas das principais firmas do país estão localizadas nesta região, o que significa escala suficiente para investimento interno em inovação, além das pequenas e médias empresas especializadas no suprimento de bens e serviços ambientais.

\section{b) Cooperação}

A cooperação nessa região surgiu da inter-relação entre os setores causadores dos problemas ambientais com aqueles que eram capazes de resolvê-los, tendo como 'pano de fundo’ o aumento da regulação. As indústrias mais poluentes, como a mineração de carvão, siderúrgica e química, são as líderes na demanda por soluções ambientais e forçaram seus fornecedores - através do poder de mercado que exerciam devido ao seu tamanho e importância - a desenvolver soluções de engenharia mecânica para desenvolver tecnologias de redução de poluição, contaminação e rejeitos industriais. Assim, as tecnologias ambientais surgem na região: através de soluções internas aos departamentos de pesquisa da indústria do aço, da fundação de novas empresas especializadas em engenharia e outras formas de busca externa.

É comum, por exemplo, a cooperação entre as firmas do aço, energia e mineração. Cerca de metade do investimento alemão em tecnologias ambientais é realizado em NorthRhine Westphalia. Por outro lado, existe a tradição de cooperação das autoridades locais, especialmente em suprimento de energia e purificação de água, disponibilidade de depósitos de lixo e locais para incineração e experiência no transporte de materiais perigosos como lixo tóxico.

Alguns exemplos importantes de cooperação entre as firmas podem ser citados: $\imath$ ) entre empresas de mineração, aço e energia (Ruhrkohle, RWE, Thyssen, Hoesch), empresas especializadas em gestão de resíduos (Heitkamp, Edelhoff) e produtores afetados (Opel, 
Bayer) com o objetivo de desenvolver novos conceitos em reciclagem de automóveis; ii) entre Thyssen, RWE e as autoridades locais de Duisburg, organizando o "Entsorgungszentrum Duisburg" para desenvolver novos conceitos em transporte de lixo tóxico; e iii) entre indústrias químicas (BASF, Hoeschst, VEBA), um produtor de aço (Klöckner) e um instituto de pesquisa público, para implementar uma instalação de transformação de plásticos usados em derivados de petróleo.

\section{c) Governo}

A emergência da indústria de proteção ambiental não pode ser entendida sem considerar a participação do Estado, iniciando, dando suporte e organizando a formação dessa nova cadeia produtiva. Mais da metade dos investimentos nessa área foi feito diretamente pelo setor público, principalmente por autoridades locais. Este fato não ocorre por acaso, a necessidade de buscar saídas para a decadência da produção tradicional fez com que o governo local optasse pelas tecnologias ambientais como uma das maneiras de elevar a competitividade, alcançando assim um grande sucesso.

O investimento industrial em tecnologias ambientais foi, e ainda é induzido pelo Estado através do controle e regulação, sendo que a maior parte da regulação é federal, mas algumas partes são feitas pelo governo local. As atividades do Estado que tiveram como objetivo prover uma infra-estrutura são: $\imath$ ) organização e suporte de programas de treinamento específico; ii) fundação de institutos de pesquisa e institutos de desenvolvimento; c) fundação de centros tecnológicos ou parques industriais para produção de tecnologia ambiental.

\section{d) Pesquisa e principais tecnologias}

As empresas na região North-Rhine Westphalia estão fortemente engajadas nos programas de proteção ambiental fomentados pelo governo, no que diz respeito às atividades de pesquisa e desenvolvimento. As áreas mais desenvolvidas são aquelas relacionadas com as engenharias, em especial a mecânica, que se desenvolveram através da busca pela construção de máquinas e sistemas ambientais para diminuição ou prevenção da poluição em indústrias com alto potencial de poluição, como siderurgia e energia. A indústria de proteção ambiental se estabeleceu com muitas empresas em áreas correlatas como a de construtores de máquinas e sistemas ambientais e empresas especializadas em gestão de resíduos e reciclagem de solo. Um grande número de pequenas e médias empresas (PMEs) estão engajados em áreas como: planejamento e propaganda, desenvolvimento de software, sistemas produtivos, aparelhos para 
medir e controlar componentes especiais e materiais químicos básicos. Outras firmas estão envolvidas em atividades de transporte, biotecnologia e processamento.

Atualmente, existe naquela região uma estrutura diferenciada de firmas que foram atraídas pelas oportunidades deste mercado e que torna a região numa das mais competitivas do mundo na área de tecnologia ambiental.

\section{e) Resultados}

O reflexo do sucesso da região pode ser visto no nível de registros de patentes. Em relação ao restante do país, de onze áreas relacionadas às tecnologias ambientais, a região possui especialização produtiva em nove. A média de patentes nessas áreas é muito superior às demais regiões da Alemanha.

Cerca de 90.000 pessoas estavam trabalhando no setor ambiental privado em 1996 (mais que no setor de mineração). Isto prova que a área de tecnologias ambientais pode ser grande geradora de empregos. Alem disso, constata-se que a partir do final dos anos 80 , um número surpreendente de firmas de consultoria, planejamento e outros serviços, entraram no mercado, dobrando o número de firmas existentes e tornando-o diversificado em relação aos problemas ambientais.

\section{A Evolução do SRI Ambiental de North-Rhine Westphalia}

Esta região é tomada como referência de organização e integração da política pública regional com a proteção ambiental na indústria. Ela é considerada uma das regiões pioneiras na busca por soluções ambientais para redução da poluição (principalmente EOP). Entretanto, o futuro do SRI depende das decisões estratégicas que serão e estão sendo tomadas no atual momento considerando as oportunidades tecnológicas futuras, numa situação onde as empresas se preocupam em ser menos hostis ao meio ambiente produzindo através de processos limpos. Ao mesmo tempo, essas decisões devem levar em consideração que a concorrência mundial para o fornecimento de tecnologias ambientais apresenta notável crescimento.

\section{a) Pré-condições e surgimento do sistema}

Os problemas ambientais tais como resíduos, poluição da água e do ar, contaminação do solo e lixo tóxico, existiram por muitas décadas em North-Rhine Westphalia e estão associados ao seu crescimento econômico, uma das regiões mais importantes da Alemanha. Ela sempre foi grande produtora de bens que causam forte impacto ambiental, como carvão, ferro e aço, mas que por outro lado é fonte de matérias-primas e energia para 
grande parte da indústria. Derivada dessa produção, outras indústrias importantes se localizaram nessa região, como a indústria química e a mecânica.

Este cenário indica que se a regulação tornasse a atividade produtiva inviável devido às exigências, a prosperidade cessaria. Portanto, a solução inexorável era "limpar" a produção desses bens de suma importância para a região. Todavia, o que era inicialmente um problema, tornou-se um novo mercado lucrativo e promissor pelo fato de ter sido implantado muito cedo, num ambiente quase sem concorrência para este tipo de soluções ambientais. Atualmente, ressalta-se a vanguarda e o salto tecnológico alcançado pelas mudanças tomadas naquele período e que, no entanto, tais mudanças eram vistas como um entrave ao crescimento e uma desvantagem econômica em relação aos outros países que não haviam tomado as mesmas medidas.

\section{b) Evolução da regulação e transformações na estrutura produtiva e} tecnológica

A indústria de proteção ambiental começou a se desenvolver no início dos anos 60 na área do vale do Ruhr. Todavia, apenas no início dos anos 70 se discutiu pela primeira vez de maneira ampla a questão ambiental em North-Rhine Westphalia, o que foi crucial para o desenvolvimento de uma indústria de proteção ambiental, uma vez que dessas discussões emergiam soluções de política de inovação direcionadas para esses problemas.

A regulação relativa às questões ambientais seguiu a tendência mundial demandando soluções imediatas com tecnologias de remediação (EOP) da poluição, em vista do "terror" causado pelas publicações científicas a respeito dos limites do crescimento. As novas tecnologias de limpeza do carvão e de melhoria da qualidade da água produzidas na região ganharam espaço mundial, tendo como concorrentes apenas os japoneses que revezaram com os alemães a distribuição mundial de tecnologias de limpeza do carvão durante o início dos anos 80 .

No início dos anos 90, a estratégia da regulação mudou o foco de soluções EOP para Pollution Prevention (PP) e a região passou a investir na prevenção da poluição através de processos limpos. Nesse momento, uma ampla gama de empresas se envolveu nesse novo mercado. Os grupos de empresas mais importantes foram: i) construtores de máquinas e sistemas (plantas) industriais limpas; ii) empresas de mineração e de energia que diversificaram, fundando novas companhias de gestão de resíduos; iii) empresas locais que anunciaram novas políticas de reciclagem (montadoras de veículos e indústria química); iv) empresas de gestão de resíduos e tratamento de solos; etc. 


\section{c) Desenvolvimento da infra-estrutura e canais de difusão tecnológica}

Entre os anos de 1989 a 1994, foi criado na Alemanha o Programa de Pesquisa Ambiental e Tecnologias Ambientais, que já no início dos anos 90, mudou definitivamente a estratégia de soluções imediatas EOP para o desenvolvimento de produtos e processos limpos, com busca por parcerias e formação de centros de excelência em tecnologias, engenharia e marketing ambientais com objetivo de aumentar a produtividade e competitividade da região, além de gerar empregos.

Em 1991, o governo alemão criou o programa federal para o meio ambiente, com o objetivo de fomentar o desenvolvimento e promover a difusão de tecnologias ambientais principalmente para as pequenas e médias empresas. Em 1997 o investimento para pesquisa em tecnologias ambientais alcançou a cifra de 378,8 milhões de Euros. Em 2000, foi criado o Programa Biotecnologia, um novo programa ligado à promoção de tecnologias ambientais.

Esses programas têm o objetivo de manter o poder de mercado na área de tecnologia ambiental obtido através dos anos. Para isso, a diversificação dos produtos e processos teve que acompanhar a fronteira tecnológica não apenas, como no passado, limpando a "sujeira" causada pela indústria, mas evitando que ela ocorra.

\section{d) Caminhos para a cooperação}

$\mathrm{Na}$ realidade, a região de North-Rhine Westphalia possui uma tradição de cooperação para solução de problemas ambientais desde o início dos anos 70, quando as firmas geradoras da poluição buscavam resolver seus problemas interagindo com firmas locais, que desenvolviam tecnologias especiais para isso. Por outro lado, as grandes firmas poluidoras exigiam um comportamento ambientalmente correto de seus fornecedores.

A cooperação seguiu um processo natural quando a indústria encontrou obstáculos para o crescimento sujeito à regulação ambiental. A crise causada pela regulação apenas agravou a situação decadente da indústria tradicional (e poluidora) do vale do Ruhr, baseada em mineração e siderurgia. A única opção foi a união entre os membros da cadeia produtiva para encontrar soluções comuns que mantivessem a viabilidade dos negócios na região. $\mathrm{O}$ governo aparece como parceiro, fornecendo a infra-estrutura científico-tecnológica e financeira, e assim a cadeia de produção se completou.

Torna-se importante salientar que o governo alemão concede poderes significativos aos estados para que estes possam gerir suas próprias políticas industriais e alocar recursos diretamente. Assim, é possível identificar as necessidades e desobstruir mais rapidamente a 
passagem do crescimento, o que lhes confere ferramentas suficientes para incentivar a cooperação de maneira mais próxima e direta.

\section{e) Estágio atual e perspectiva para o futuro}

A perspectiva de um acirramento da regulação e de que o processo de combate à poluição industrial é irreversível torna a região de North-Rhine Westphalia privilegiada e requisitada por outras regiões que ainda estão em busca de processos com tecnologias limpas. Ao mesmo tempo, é possível visualizar muitas outras regiões e países se engajando nesse mercado de tecnologias ambientais e reduzindo a lucratividade inicialmente auferida, o que aponta para a necessidade de tornar a pesquisa ambiental uma prioridade no intuito de manter esta região como área de excelência em tecnologias ambientais, mesmo em áreas distintas daquelas existentes no início do sistema. Ainda assim, pode-se considerar a região alemã como um caso de sucesso, muito difícil de ser imitado por outras regiões.

\section{Considerações Finais}

$\mathrm{Na}$ primeira seção, algumas dimensões (os principais atores, a cooperação, o governo, pesquisa e tecnologias principais e resultados) foram analisadas com o objetivo de se identificar às características essenciais do sistema de inovação ambiental alemão. Dentre essas dimensões, duas delas merecem destaque no caso alemão: o governo desempenha um papel central entre os atores na medida em que ele participa investindo e provendo a infra-estrutura tecnológica. O segundo é a tradição de cooperação presente no sistema de North-Rhine Westphalia. Pode-se notar que a cooperação é a tarefa mais difícil na constituição de um sistema inovativo e é função do agente que exerce a governança tomar a frente das negociações.

As tecnologias principais revelam que há muito tempo não se pensa mais em soluções (EOP). A fronteira tecnológica está em energia e combustíveis renováveis, saneamento, reciclagem, tratamento e reaproveitamento de rejeitos, e assim por diante. As firmas estão buscando entender e tratar seus produtos tendo em vista todo o seu ciclo de vida, desde a fonte de matérias-primas até a disposição ou reciclagem. A demanda governamental por soluções ambientais também move este mercado, promovendo o desenvolvimento de sistemas de monitoramento e melhoria da qualidade de vida nas cidades e no campo.

Na segunda seção, foi apresentada a evolução do SRI ambiental alemão. Um aspecto importante a ser ressaltado é o fato de a regulação ser o primeiro e o mais importante 
instrumento de estímulo à inovação ambiental, sendo que o SRI ambiental alemão, um dos mais antigos, foi formado e se tornou referência mundial em tecnologia ambiental devido à aplicação precoce da regulação no combate à poluição industrial naquela região. Ao compreender que a regulação ambiental era um processo irreversível, a região de North-Rhine Westphalia obteve êxito na inovação e na inserção no mercado de tecnologias ambientais, estando sempre um passo a frente dos países e/ou regiões que retardaram as mudanças internas.

\section{Referências bibliográficas}

BARTON, J. R. (1998). La Dimensión Norte-Sur de las Industrias de Limpieza Ambiental y la Difusión de Tecnologías Limpias. In: Revista de la CEPAL, $\mathrm{n}^{\circ} 64$.

DOLOREUX, D. \& PARTO, S. (2004). Regional Innovation Systems: A Critical Synthesis, In: Institute for New Technologies (INTECH) discussion paper n. 2004-17, United Nations University.

KEMP, R.; SMITH, K. \& BECHER, G. (2000). How We Should Study the Relationship between Environmental Regulation and Innovation?. In: HEMMELSKAMP, J.; RENNINGS, K \& LEONE, F. (Eds.), Innovation-Oriented Environmental Regulation: Theoretical Approaches and Empirical Analysis, Heidelberg: Physical Verlag.

OECD (1985). Environmental Policy and Technical Change, Paris: OCDE.

PORTER, M. (1990). The Competitive Advantage of Nations, London: Macmillan.

PORTER, M (1996). “America's Green Strategy”. In: WELFORD, R. \& STANKEY, R The Earthscan Reader in Business and the Environment, London: Earthscan.

PORTER, M \& VAN DER LINDE, C. (1995a). "Toward a New Conception of the Environment-Competitiveness Relationship", In: Journal of Economic Perspectives, vol. 9, $\mathrm{n}^{\circ} 4$.

PORTER, M \& VAN DER LINDE, C. (1995b). "Green and Competitive: Ending the Stalemate. In: Harvard Business Review, n. 73 (5).

SKEA, J. \& SMITH, A. (1998). "Integrating Pollution Control”. In: LOWE, P. \& WARD, S. (Eds.), British Environmental Policy and Europe: politics and policy in transition, London: Routledge.

SKEA, J. (2000). "Environmental Technology". In: FOLMER, H. \& GABEL, H. L. (Eds.), Principles of Environmental and Resource Economics: a guide for students and decision-makers, Cheltenham, UK: Edward Elgar.

REHFELD,D.; NORDHAUSE-JANZ, J.; HILBERT, J. \& HEINZE, R. (1998). "Industrial Clusters and the Governance of Change". In: BRACZIK, H.-J.; COOKE, P. \& HEIDEREICH, M. (Eds.), Regional Innovation Systems: The Role of Governances in a Globalized World, UCL Press: London. 